\title{
FLAVONOIDS FROM Campanula cephalotes
}

By two-dimensional paper chromatography we have found five substances of flavonoid nature in the herb Campanula cephalotes Nakai collected in the flowering phase in the Buryat ASSR.

To isolate the individual flavonoids, the herb was extracted with $96 \%, 70 \%$, and $40 \%$ ethanol by continuous percolation. The combined extracts were concentrated under vacuum to small volume, and the residue was treated with chloroform and was then chromatographed on a column of polyamide sorbent. Two flavonoid substances were obtained.

Substance (I) $(0.3 \%), \mathrm{C}_{22} \mathrm{H}_{22} \mathrm{O}_{12}$, yellow needles with $\mathrm{mp} 225-226^{\circ} \mathrm{C}$ (from $70 \%$ ethanol), $[\alpha]_{\mathrm{D}}^{20}-43.2^{\circ}$ (c 0.5 ; dimethylformamide). UV spectrum (ethanol), $\lambda_{\max }, \mathrm{nm}: 362,305,258$. Qualitative reactions and spectroscopy in the UV region with additives showed that this substance was a flavonol glycoside with free hydroxy groups in the 5, $3^{\prime}$, and $4^{\prime}$ positions. Acid hydrolysis gave the aglycone (yield 67\%) and D-galac-

tose. The aglycone had the composition $\mathrm{C}_{16} \mathrm{H}_{12} \mathrm{O}_{7}, \mathrm{mp} 294-295^{\circ} \mathrm{C}$ from ethanol ( $\mathrm{mp}$ of the acetate $190-192^{\circ} \mathrm{C}$ ).

On the basis of the bathochromy in the presence of diagnostic reagents and the products of alkaline degradation and of demethylation, the aglycone was identified as rhamnetin. The cleavage of glycoside (I) with emulsin, the rate of hydrolysis, and the UV spectrum showed that the galactose in it is present in position 3 and is attached by a $\beta$-glycosidic bond.

The results of IR spectroscopy and a comparison of $[M]_{D}$ of the glycoside with $[\mathrm{M}]_{\mathrm{D}}$ of phenyl $\beta-\mathrm{D}-$ galactopyranoside enabled substance (I) to be characterized as rhamnetin 3-O- $\beta-D-g a l a c t o p y r a n o s i d e ~[1]$.

Substance (II), $\mathrm{C}_{16} \mathrm{H}_{12} \mathrm{O}_{\eta}$, formed yellow acicular crystals with mp 292-294 ${ }^{\circ} \mathrm{C}$. By its physicochemical properties and UV and IR spectra it was identified as rhamnetin.

\section{LITERATURE CITED}

1. I. P. Kovalev and V. I. Litvinenko, Khim. Prirodn. Soedin., 233 (1965).

Leningrad Chemical and Pharmaceutical Institute. Translated from Khimiya Prirodnykh Soedinenii, No. 3, p. 392, May-June, 1972. Original article submitted January 25, 1972.

- 1974 Consultants Bureau, a division of Plenum Publishing Corporation, 227 W'est 17th Street, New York, N. Y. 10011. No part of this publication may be reproduced, stored in a retrieval system, or transmitted, in any form or by any means, electronic, mechanical, photocopying, microfilming, recording or otherwise, without written permission of the publisher. A copy of this article is available from the publisher for $\$ 15.00$. 